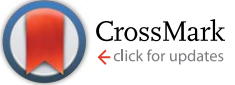

Cite this: RSC Adv., 2017, 7, 1981

\title{
DBN-based ionic liquids with high capability for the dissolution of wool keratin $\uparrow$
}

\author{
Xue Liu, ${ }^{\text {ab }}$ Yi Nie, $^{\text {*b }}$ Xianglei Meng, ${ }^{\text {b }}$ Zhenlei Zhang, ${ }^{\mathrm{b}}$ Xiangping Zhang ${ }^{\mathrm{b}}$ \\ and Suojiang Zhang*b
}

An increasing interest has been manifested in the use of ionic liquids (ILs) as solvents for the dissolution of wool keratin due to their tunable and excellent properties, despite the fact that it is still a challenge that ILs with different structures have distinct dissolution capabilities for wool. In this study, a series of 1,5diazabicyclo[4.3.0]-non-5-ene (DBN)-based ionic liquids with different anions have been designed and employed for the dissolution of wool keratin. The effects of the ILs structures on their dissolution capabilities were systematically studied, and the optimal IL with high dissolution capability for goat wool was finally obtained by overall considering the time taken for the goat wool complete dissolution and the properties of the regenerated keratin. It was found that both cations and anions, acting as the regulators for polarity $\left(E_{\mathrm{T}}^{N}\right)$ and hydrogen-bond basicity $(\beta)$ of the ILs, have significant influence on the dissolution capabilities of the ILs, which play an important role in the design and synthesis of new functional ILs for the dissolution of wool keratin. Furthermore, the time taken for the complete dissolution of $8 \mathrm{wt} \%$ goat wool in the optimum IL 1-ethyl-1,5-diazabicyclo[4.3.0]-non-5-enium diethylphosphate ([DBNE]DEP) is $3 \mathrm{~h}$ at $393 \mathrm{~K}$, and the relative crystallinity, content of $\alpha$-helix, and decomposition temperature of the regenerated keratin from [DBNE]DEP are higher $(60.99 \%, 57.88 \%$, and $521 \mathrm{~K}$, respectively) than that from other ILs. Moreover, the break ratio of the disulfide bond is reduced to only $53.46 \%$. In addition, [DBNE]DEP could be easily reused at least 5 times with stable structures and good dissolving ability, and the non-newtonian index, $n$, of the DEP IL/keratin solutions is all about 0.8 , which means that the DEP IL/keratin solution has good prospects in terms of spinning.

Received 31st October 2016 Accepted 12th December 2016 DOI: $10.1039 / c 6 r a 26057 h$ www.rsc.org/advances
Efficient dissolution of keratin is the basis of reusing waste wool keratin. ${ }^{8}$ However, it is difficult to dissolve wool keratin in conventional solvents due to the tight packing of the secondary structures in the polypeptide as well as the inter-and intramolecular strong hydrogen bonds and disulfide bonds., ${ }^{\mathbf{9 1 0}}$ Many methods, such as reduction, ${ }^{\mathbf{1 , 1 1 , 1 2}}$ oxidation, ${ }^{\mathbf{1 , 1 2 , 1 3}}$ sulfitolysis, ${ }^{\mathbf{1 , 1 4 , 1 5}}$ and acid-alkali, have been explored to dissolve wool. ${ }^{\mathbf{1 6}}$ However, the keratins regenerated from these traditional methods have a lower molecular weight and poor spinnability due to serious damage and degradation. Moreover, the solvents used in these traditional methods are often toxic and difficult to recycle.

New and efficient solvents are required to help unlock the promise of keratin dissolution, and in this regard, the field of ILs might actually live up to its tremendous potential., ${ }^{77}$ As a new class of designer solvents, ILs can dissolve a large number of biopolymers, such as, feathers, ${ }^{10,18,19}$ cellulose, ${ }^{20-23}$ wool, ${ }^{2,24,25}$ chitosan, ${ }^{26,27}$ lignin, ${ }^{28}$ and silk, ${ }^{29,30}$ with high efficiency, due to their unique properties such as high thermal stability, tunable properties, and good dissolving ability. ${ }^{8}$ Promising results for the dissolution of keratin in ILs have also been obtained. Xie et al. reported the first example of a single solvent that was able to dissolve the wool keratin and found that 1-allyl-3-methylimidazolium chloride
273165, China

${ }^{b}$ Key Laboratory of Green Process and Engineering, State Key Laboratory of Multiphase Complex Systems, Beijing Key Laboratory of Ionic Liquids Clean Process, Institute of Process Engineering, Chinese Academy of Sciences, Beijing, 100190, China. E-mail: ynie@ipe.ac.cn; sjzhang@ipe.ac.cn

$\dagger$ Electronic supplementary information (ESI) available. See DOI: 10.1039/c6ra26057h 
([Amim $] \mathrm{Cl}$ ) and 1-butyl-3-methylimidazolium chloride ([Bmim]Cl) have good dissolution capabilities. ${ }^{7}$ Idris and co-workers found that turkey feathers dissolve in [Amim] $\mathrm{Cl},[\mathrm{Bmim}] \mathrm{Cl}$, and [choline] thioglycolate up to $45 \mathrm{wt} \%$ at $403 \mathrm{~K}$ for $10 \mathrm{~h}$ under nitrogen atmosphere. Moreover, gel electrophoresis results show that the water soluble fraction has a lower molecular weight but it is still substantially polymeric. ${ }^{10}$ A number of ILs and deep eutectic mixtures were also investigated by the same researchers for the dissolution of wool and it was found that the highest limiting solubility (up to $475 \mathrm{mg}$ wool per gram of solvent) was achieved in [Amim]DCA. ${ }^{2}$ The effects of the structures of ILs on the dissolution time of wool keratin and the properties of the regenerated keratin were studied in our previous work. ${ }^{8}$ The results show that both cations and anions have effects on the dissolution capability and 1ethyl-3-methylimidazolium dimethylphosphate ([Emim]DMP) requires a shorter time to dissolve the same amount of keratin than that of other ILs at $403 \mathrm{~K}$. Although there have been extensive studies on the dissolution of keratin in ILs, research on the relationship between their structures and dissolution capability is still a challenging task.

Considering the high dissolution capability of the phosphate-based ILs, ${ }^{8}$ herein, a number of ILs were designed to study the effects of ILs structures on their dissolution capabilities by investigating the dissolution time and properties of the regenerated keratin. The results indicate that both cations and anions have effects on the dissolution capability of the ILs and the higher the value of $E_{\mathrm{T}}^{\mathrm{N}}$ and $\beta$, the shorter the time required to dissolve the keratin. The properties of the keratin regenerated from different ILs were studied using a series of methods, such as X-ray diffraction, nuclear magnetic resonance spectroscopy, disulfide-sulfhydryl analysis, and thermogravimetric analysis. Moreover, the DEP-based IL/keratin solution has good prospects in terms of spinning, and [DBNE]DEP IL exhibits an excellent recycling performance. Thus, the relationship between the structure of ILs and dissolution capability play an increasingly important role in the dissolution of wool keratin and may open new avenues for the design and synthesis of new functional ILs in the future.

\section{Experiment}

\subsection{Materials}

Goat wool was provided by Henan Zhongrong Biotechnology Co., Ltd, and shattered into small pieces before dissolution. 1,5Diazobicyclo[4.3.0]non-5-ene (DBN) was purchased from the Beijing Huawei Ruike Co., Ltd. Triethyl phosphate and trimethyl phosphate $(\geq 98 \%)$ were supplied by the Tokyo Chemical Industry Co., Ltd. $N$-Alkyl imidazole ( $\geq 98 \%)$ was provided by Sinopharm Chemical Reagent Co., Ltd. Acetic acid was purchased from Xilong Chemical Industry Co., Ltd.

\subsection{Synthesis of ionic liquids}

1-Ethyl-1,5-diazabicyclo[4.3.0]-non-5-enium diethylphosphate ([DBNE]DEP) and 1-methyl-1,5-diazabicyclo[4.3.0]non-5-enium dimethyl phosphate ([DBNM]DMP) were synthesized by mixing equimolar amounts of DBN (1,5-diazabicyclo[4.3.0]-non-5- ene) and the corresponding trialkyl phosphate at $353 \mathrm{~K}$ for $12 \mathrm{~h}$. The detailed synthetic procedure for 1,5-diazabicyclo [4.3.0]non-5-enium acetate ([DBNH]OAc) followed that reported by King et al. ${ }^{31}$ 1-Ethyl-3-methylimidazolium diethylphosphate ([Emim]DEP) and 1-ethyl-3-methylimidazolium dimethylphosphate ([Emim]DMP) were prepared by mixing $N$ methyl imidazole ( $N$-ethylimidazole) and triethylphosphate (trimethyl phosphate) under the previously reported conditions. ${ }^{32,33}$ The structures of the ILs are shown in Scheme 1. All ILs were purified by washing with ether and dried using an oil pump vacuum at $353 \mathrm{~K}$ for several days to remove any residual water. The water content of the ILs was measured using a C20 Coulometric KF Titrator (Mettler Toledo) before use (Table S1, ESI $\dagger$ ). The purity and structure of these ILs were analyzed via NMR and electrospray mass spectrometry (see ESI $\dagger$ ).

\subsection{Dissolution and regeneration of wool keratin}

About $1.3 \mathrm{~g}$ goat wool was added to the ILs, where $8 \mathrm{wt} \%$ was chosen as the mass ratio of the wool and ILs, and then magnetically stirred in a tube at $393 \mathrm{~K}$. The degree of dissolution of wool keratin at a given time was investigated using an Olympus microscope via light scattering with a $200 \times$ objective lens. After the wool keratin was dissolved, it was precipitated from the ILs solution by the addition of ethanol at room temperature and separated by centrifugation for $5 \mathrm{~min}$ at $10000 \mathrm{rpm}$. The regenerated keratin was dried at $343 \mathrm{~K}$ for 2 days.

\subsection{Characterization of the regenerated keratin}

Nuclear magnetic resonance spectroscopy (NMR). NMR spectra were obtained at $600 \mathrm{MHz}$ using a Bruker spectrometer. All samples were measured as solutions in the deuterated dimethyl sulfoxide. Solid state ${ }^{13} \mathrm{C}$ NMR spectra of wool and

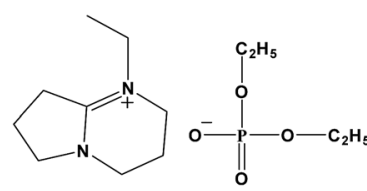

[DBNE]DEP

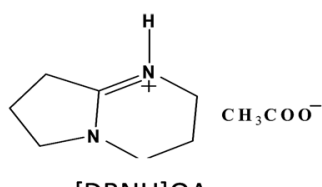

[DBNH]OAC

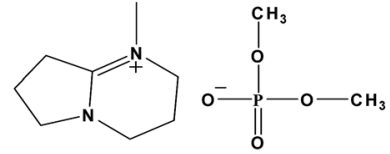

[DBNM]DMP

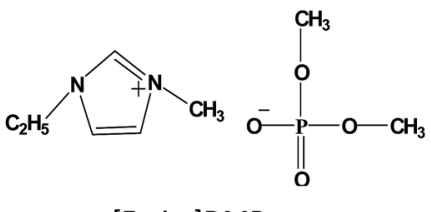

[Emim]DMP

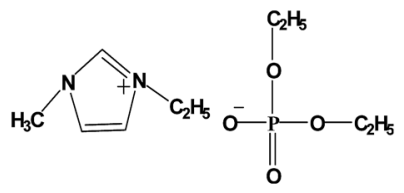

[Emim]DEP

Scheme 1 Chemical structures of the ILs used in this study 
regenerated keratin were acquired by a $400 \mathrm{MHz}$ WB solid-state NMR spectrometer using a $4 \mathrm{~mm}$ rotor under the following conditions: RF field of $62.5 \mathrm{kHz}, 90^{\circ}$ pulse, $4.17 \mu \mathrm{s}$, and $101 \mathrm{~W}$.

Hydrogen-bond basicity and polarity. The solvatochromic dyes, 2,6-diphenyl-4-(2,4,6-triphenylpyridinio)phenolate (Reinhardt's dye 30), 4-nitroaniline, and $N, N$-diethyl-4-nitroaniline were used to determine the polarity $\left(E_{\mathrm{T}}^{\mathrm{N}}\right)$ and hydrogen-bond basicity $(\beta)$ of ILs. The dyes were added to a small vessel as a concentrated dry dichloromethane solution, and then dichloromethane was carefully removed before the ILs were added. The mixture was thoroughly stirred. The ionic liquids solutions were transferred to a quartz cuvette, and then placed into the sample cell of a UV 2550 UV-vis spectrophotometer. The temperature of the sample cell was maintained at $298 \mathrm{~K}$ by water circulation. From the wavelength at the maximum absorption $\left(\lambda_{\max }\right)$ determined, the $E_{\mathrm{T}}^{\mathrm{N}}$ and $\beta$ were calculated using the following equations: ${ }^{34,35}$

$$
\begin{gathered}
\nu_{(\text {dye })}=1 /\left(10^{-4} \times \lambda_{\max (\text { dye })}\right) \\
E_{\mathrm{T}}(30)\left[\mathrm{kcal} \mathrm{mol}^{-1}\right]=28591 / \lambda_{\max }[\mathrm{nm}] \\
E_{\mathrm{T}}^{\mathrm{N}}(30)=\left(E_{T}(30)-30.7\right) / 32.4 \\
\beta=\left(10.35 \nu_{(N, N \text {-diethyl-4-nitroaniline })}+2.64-\nu_{(4-\text {-nitroaniline })}\right) / 2.80
\end{gathered}
$$

Disulfide-sulfhydryl. Colorimetric reactions were carried out under the conditions described by Thannhauser et al. (1987). ${ }^{36}$ The content of disulfide group was determined by calculating the difference between the thiol group content before and after the reduction of the disulfide bonds with sulfite. Free thiol groups were studied using a solid phase assay under the conditions reported by Chan and Wasserman (1993). ${ }^{37}$ An extinction coefficient of $13600 \mathrm{M}^{-1} \mathrm{~cm}^{-1}$ was used to calculate the number of sulfur-containing groups. ${ }^{38}$

Fourier transform infrared spectroscopy (FT-IR). Fourier transform infrared spectra of the samples were acquired in the wavenumber range of 500-4000 $\mathrm{cm}^{-1}$ using a Thermo Nicolet 380 instrument. Spectra were obtained under the conditions of 32 scans and a resolution of $4 \mathrm{~cm}^{-1}$. All the spectra were baseline corrected.

Crystallinity analysis [X-ray diffraction (XRD)]. X-ray diffraction was employed to examine the crystalline structures of wool and regenerated keratin. Data were obtained using a Bruker D8 Focus instrument, and the X-ray tube was operated at $45 \mathrm{kV}$ and $200 \mathrm{~mA}$ with $2 \theta$ ranging from $5^{\circ}$ to $50^{\circ}$ at a scan speed of 0.05 $\mathrm{s}^{-1}$. The crystallinity index (C.I.), which indicates the relative degree of crystallinity, has been used to characterize the keratin fibers for a long time and was calculated using the $L$. Segal method as shown in the following equation:

$$
\text { C.I. }=\left(I_{9}-I_{14}\right) / I_{9}
$$

where C.I. is the crystallinity index, $I_{9}$ is the maximal intensity of the crystal lattice diffraction with a $2 \theta$ at around $9^{\circ}$, whereas $I_{14}$ is the minimal diffraction intensity with $2 \theta$ at around $14^{\circ}$. It is believed that a high C.I. value indicates high crystallinity of the sample. ${ }^{39,40}$

Thermogravimetric analysis (TGA). The thermal stability of the wool and regenerated keratin was investigated via TGA (Q5000 V3.15 Build 263). Approximately 5-10 $\mathrm{mg}$ of the sample was heated from 303 to $1173 \mathrm{~K}$ under a dynamic nitrogen atmosphere at a heating rate of $10 \mathrm{~K} \mathrm{~min}^{-1}$.

Rheological measurement of the keratin solutions. The rheological properties of the keratin solutions were studied using a parallel plate type rheometer (Discovery HR-2 hybrid rheometer). First, the solutions were degassed under vacuum for $24 \mathrm{~h}$ before measurement. The measurements were performed within the temperature range of 313-393 $\mathrm{K}$, and the shear rate $(\gamma)$ was $0-600 \mathrm{~s}^{-1}$. The non-newtonian index is the degree of the non-Newton fluid deviating from the Newton fluid. As is known, the power law relationship of the Ostwald de Waele model is a useful form of expressing the flow behavior,

$$
\sigma=K \gamma^{n}
$$

where $\gamma$ (inverse seconds) is the shear rate, $\sigma$ (pascal) indicates the shear stress, and $n$ and $K$ are the non-newtonian index and the consistency index constants, respectively. The nonnewtonian index, $n$, is the slope of $\log \sigma=f(\log \gamma) .^{41,42}$

\section{Results and discussion}

\subsection{Dissolution process}

According to the previous reports, ${ }^{7,10}$ temperature is an important influencing factor for wool dissolution, which affects the solubility of the wool keratin and properties of the regenerated keratin. Based on our previous study, the experiments were conducted at $393 \mathrm{~K}$. Moreover, the mass ratio of wool keratin to ILs also affects the dissolution of wool keratin; therefore, herein, $8 \mathrm{wt} \%$ was chosen as the consistent percentage.

A microscope was used to observe the dissolving process of the wool fibers in the ILs. From Fig. 1, it can be seen that the wool keratin fibers were initially thick and long and gradually became thinner and shorter with the increasing dissolution time. Finally, they completely dissolved in the IL.

The yields of the keratin regenerated from different IL solutions were also studied. Table 1 indicates that although the dissolution time of [DBNH]OAc is shorter than that of other ILs used here, the yield of keratin regenerated from the [DBNH]OAc solution is the lowest. The yield of keratin regenerated from the
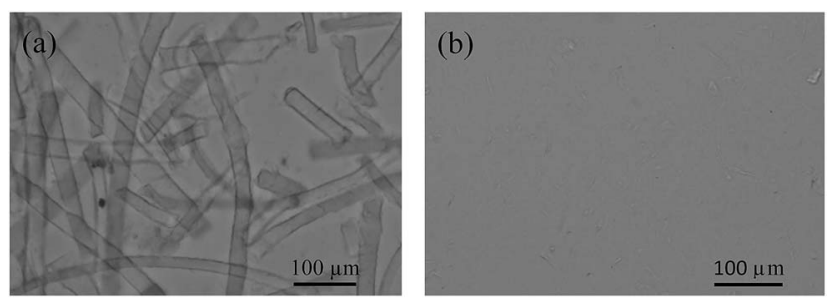

Fig. 1 Dissolution process of wool fibers in [DBNE]DEP after 5 min (a) and $3 \mathrm{~h}(\mathrm{~b})$ 
Table 1 Yields of the regenerated keratin

\begin{tabular}{lll}
\hline $\mathrm{IL}$ & Time $(\mathrm{h})$ & Yield $\left(\mathrm{g} \mathrm{g}^{-1}\right)$ \\
\hline$[$ Emim]DEP & 1.5 & 0.3553 \\
[Emim]DMP & 2.5 & 0.3118 \\
[DBNE]DEP & 3 & 0.4471 \\
[DBNM]DMP & 3.5 & 0.4000 \\
{$[$ DBNH]OAc } & 0.33 & 0.1697
\end{tabular}

[DBNE]DEP solution is higher than that regenerated from the other IL solutions. Therefore, the optimal IL should be obtained by overall considering the time taken to completely dissolve 8 wt $\%$ keratin, the yield of the regenerated keratin, and the properties of the regenerated keratin.

\subsection{Effect of the structure of the IL on the time taken to dissolve the wool keratin}

The dissolution capabilities of the ILs with different anions for keratin were investigated by measuring the time for the complete dissolution of $8 \mathrm{wt} \%$ keratin in each IL, and the results are shown in Table 2 . Wool keratin ( $8 \mathrm{wt} \%$ ) can be completely dissolved by all the ILs at $393 \mathrm{~K}$. The dissolution time were $0.33,3$, and $3.5 \mathrm{~h}$ by using [DBNH]OAc, [DBNE]DEP, and [DBNM]DMP, respectively. According to the previous report, ${ }^{\mathbf{4 3}}$ hydrogen bond interactions might be the most important intermolecular interactions in the ILs. Therefore, polarity $\left(E_{\mathrm{T}}^{\mathrm{N}}\right)$ and hydrogen bond basicity $(\beta)$ were determined to further understand the relationship between the structure of the IL and dissolution time, and this data is presented in Table 2. Since [DBNE]DEP has stronger hydrogen bond basicity $(\beta=$ 1.11) than that of $[\mathrm{DBNM}] \mathrm{DMP}(\beta=1.02)$, a shorter time to dissolve wool keratin in [DBNE]DEP compared to that of [DBNM]DMP is expected. The same rationale can be used to understand the different dissolution time of [Emim]DEP $(\beta=$ 1.09) vs. [Emim]DMP $(\beta=1.01)$. Unexpectedly, the dissolution time of $[\mathrm{DBNH}] \mathrm{OAc}$ was shorter than that of other ILs although its hydrogen bond basicity value $(\beta=0.99)$ was the lowest. On the other hand, note that the polarity parameter $\left(E_{\mathrm{T}}^{\mathrm{N}}=0.67\right)$ of $[\mathrm{DBNH}] \mathrm{OAc}$ was the highest, which probably led to the optimal dissolution time.

The effect of cations on the dissolution time for wool keratin was also investigated using the same method, and the results are listed in Table 2 . It can be seen that the dissolution times were $1.5 \mathrm{~h}$ and $3 \mathrm{~h}$ by using [Emim]DEP and [DBNE]DEP,

Table 2 Physical properties and dissolution times of ILs ${ }^{a}$

\begin{tabular}{lllll}
\hline IL & $E_{\mathrm{T}}$ & $E_{\mathrm{T}}^{\mathrm{N}}$ & $\beta$ & Time (h) \\
\hline [DBNH]OAc & 52.41 & 0.67 & 0.99 & 0.33 \\
[DBNE]DEP & 45.78 & 0.47 & 1.11 & 3 \\
[DBNM]DMP & 46.25 & 0.48 & 1.02 & 3.5 \\
[Emim]DEP & 50.40 & 0.60 & 1.09 & 1.5 \\
[Emim]DMP & 50.89 & 0.62 & 1.01 & 2.5
\end{tabular}

${ }^{a}$ Experiments were conducted at $393 \mathrm{~K}$ with $8 \mathrm{wt} \%$ wool keratin. respectively, which indirectly show that [Emim]DEP has a greater ability to dissolve the wool keratin than that of [DBNE] DEP. From the results, it was also found that the polarity parameter of $\left[\right.$ Emim]DEP $\left(E_{\mathrm{T}}^{\mathrm{N}}=0.60\right)$ is obviously higher than that of [DBNE]DEP $\left(E_{\mathrm{T}}^{\mathrm{N}}=0.47\right)$, which follows a trend opposite to that of the dissolution time. This trend was also proven by the difference between the dissolution time of [Emim]DMP $\left(E_{\mathrm{T}}^{\mathrm{N}}=\right.$ $0.62)$ and $[\mathrm{DBNM}] \mathrm{DMP}\left(E_{\mathrm{T}}^{\mathrm{N}}=0.48\right)$. Hence, cations affect the dissolution time by influencing the polarity of the ILs. Briefly, the structures of the ILs play an important role in the dissolution process of goat wool by modulating the polarity and hydrogen bond basicity of the ILs.

\subsection{Effect of the structure of the IL on the properties of the regenerated keratin}

Crystallinity analysis. The properties of the regenerated keratins, including crystallinity, $\alpha$-helix and disulfide bond contents, and thermal stability, is another factor to evaluate the dissolution capability of a solvent for goat wool. The crystallinity of the keratin regenerated from different ILs was studied via $\mathrm{X}$ ray diffraction. From Fig. 2, it is clear that two crystal structures are typically observed from the patterns of the regenerated keratins and raw wool. According to previous reports, ${ }^{2,7}$ the large peak at around $9^{\circ}$ is attributed to the $\alpha$-helix structure and the other peak at around $20^{\circ}$ is due to the $\beta$-sheet structure. It can also be seen that the diffraction patterns of the regenerated keratins are similar to that of the raw wool, with the peaks at around $9^{\circ}$ being significantly weaker for the regenerated keratins than that of the raw wool. This phenomenon indicates that the regenerated keratins have a lower content of $\alpha$-helix structure, which is also confirmed by the trend of $C_{\mathrm{I}}$ value, discussed later.

$C_{\mathrm{I}}$ is the relative degree of crystallinity of the regenerated keratin compared with that of the raw wool. Fig. 3 shows that the regenerated keratins have lower crystallinity compared to that of the raw wool, which suggests that the regenerated keratins could not completely reconstruct the tight arrangement of the polypeptides existing in the raw wool. Especially, the keratin regenerated from [DBNH]OAc has the lowest $C_{\mathrm{I}}$ value, which indicates the most serious structural damage and

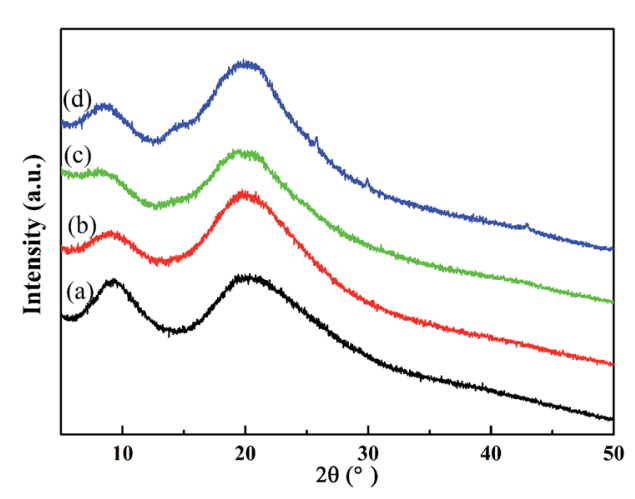

Fig. 2 XRD patterns of wool keratin (a) and keratin regenerated from [DBNE]DEP (b), [Emim]DEP (c), and [DBNH]OAc (d) solutions. 


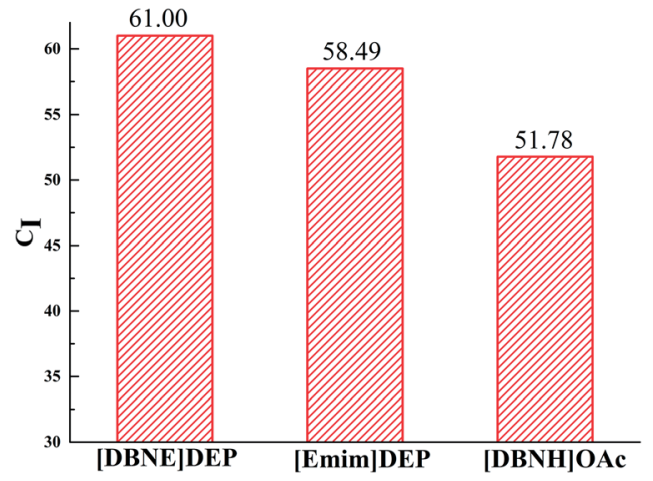

Fig. $3 C_{\text {| }}$ values of the keratin regenerated from different IL solutions.

poor spinnability. It can also be seen that the $C_{\mathrm{I}}$ value of the keratin regenerated from [DBNE]DEP is greater than that of the keratin regenerated from [Emim]DEP, which is in accordance with the trend of dissolution time. The lower the crystallinity of the keratins, the more serious the degradation suffered by the keratin. Therefore, it is important to consider the crystallinity while choosing ILs as solvents for wool keratin.

FT-IR analysis. FT-IR spectra are also used to analyze the structures of the raw wool and regenerated keratins, and these spectra are compared in Fig. 4. The characteristic absorption bands are consistent with the previously reported. ${ }^{44}$ The spectra of the keratins regenerated from different IL solutions are similar to that of the raw wool, and the main structures (amide I, II, and III) were maintained, which indicates that the peptide bonds were not strongly affected in the processes of dissolution and regeneration.

${ }^{13} \mathrm{C}$ NMR analysis. ${ }^{13} \mathrm{C}$ NMR analysis was used to investigate the subtle change in the structure, and the spectra are shown in Fig. 5(a). The chemical shifts of these samples are similar to the previously reported values. ${ }^{2,10}$ All the spectra display an asymmetric peak between 169 ppm and 174 ppm, which corresponds to the carbonyl carbons of keratin. The $\alpha$-carbons are observed at $54 \mathrm{ppm}$, whereas the $\beta$-carbons are observed at $40 \mathrm{ppm}^{2,10}$ The NMR spectra of the regenerated keratins are similar to that

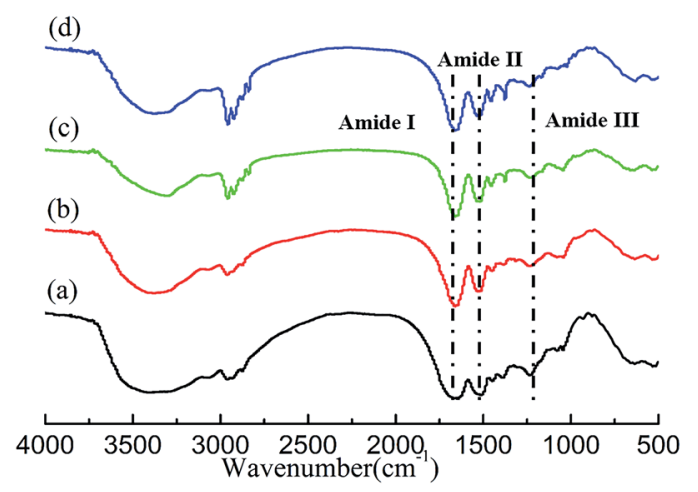

Fig. 4 The FT-IR spectra of wool keratin (a) and the keratin regenerated from [DBNE]DEP (b), [Emim]DEP (c), and [DBNH]OAc (d) solutions.

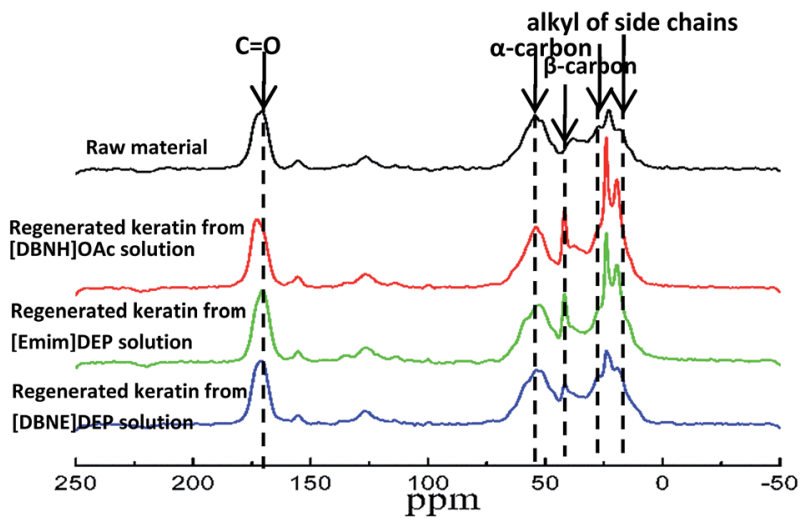

(a)
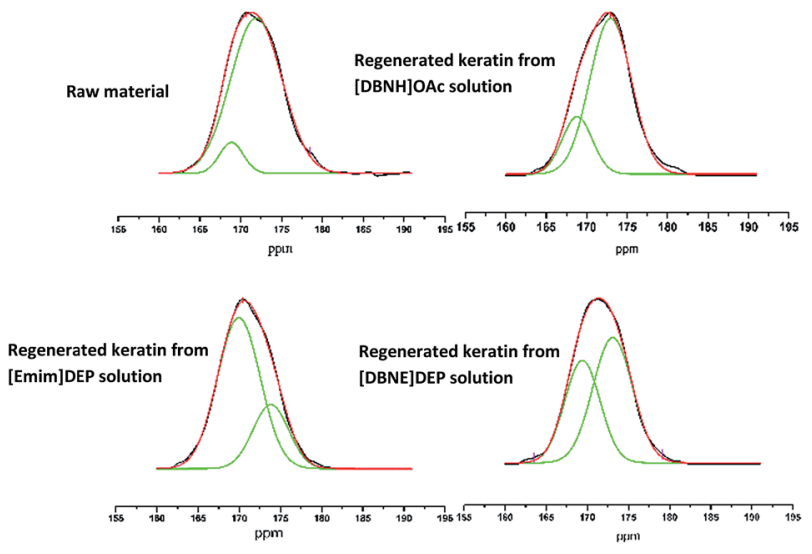

(b)

Fig. $5{ }^{13} \mathrm{C}$ NMR spectra of the raw material and the keratin regenerated from [DBNH]OAc, [Emim]DEP, and [DBNE]DEP solutions (a), and the raw material and keratin regenerated from [DBNH]OAc, [Emim]DEP, and [DBNE]DEP solutions fitted with the Gaussian fitting functions (b).

Table 3 Percentage fraction of the $\alpha$-helix and $\beta$-sheet of the raw material and regenerated $\operatorname{keratin}^{a}$

\begin{tabular}{|c|c|c|c|}
\hline Peaks & $\begin{array}{l}\text { Chemical shift } \\
\text { (ppm) }\end{array}$ & HW (ppm) & Fraction $(\%)$ \\
\hline \multicolumn{4}{|c|}{ Raw material } \\
\hline$\alpha$-Helix & 171.9 & 5.92 & $91.43 \%$ \\
\hline$\beta$-Sheet & 168.9 & 3.38 & $8.57 \%$ \\
\hline \multicolumn{4}{|c|}{ Keratin regenerated from the $[\mathrm{DBNH}] \mathrm{OAc}$ solution } \\
\hline$\alpha$-Helix & 174.03 & 1.89 & $4.53 \%$ \\
\hline$\beta$-Sheet & 171.93 & 6.45 & $95.47 \%$ \\
\hline \multicolumn{4}{|c|}{ Keratin regenerated from the $[\mathrm{Emim}] \mathrm{DEP}$ solution } \\
\hline$\alpha$-Helix & 173.8 & 4.35 & $26.55 \%$ \\
\hline$\beta$-Sheet & 169.9 & 5.18 & $73.45 \%$ \\
\hline \multicolumn{4}{|c|}{ Keratin regenerated from the $[\mathrm{DBNE}] \mathrm{DEP}$ solution } \\
\hline$\alpha$-Helix & 173.1 & 4.82 & $57.88 \%$ \\
\hline$\beta$-Sheet & 169.4 & 4.28 & $42.12 \%$ \\
\hline
\end{tabular}

${ }^{a}$ Fitted with the Gaussian function. The error in the fitting is $\sim 5 \%$. Note: "HW" is the half-width of the higher field peak. 
of the raw wool, which indicates that the main structures of the keratins were retained.

The secondary structures of keratin, including $\alpha$-helix and $\beta$ sheet, lead to a slightly different chemical shift of $\mathrm{C}=\mathrm{O}$ in the NMR spectrum. Therefore, the deconvolution of $\mathrm{C}=\mathrm{O}$ peaks was used to estimate the percentage fraction of the $\alpha$-helix and $\beta$-sheet, and the results are presented in Fig. $5(\mathrm{~b})$. The fitting of the $\mathrm{C}=\mathrm{O}$ peaks consists of two peaks. Taking the spectrum of raw wool as an example, the peak at $171.9 \mathrm{ppm}$ is assigned to the $\alpha$-helix of keratin, whereas that at $168.9 \mathrm{ppm}$ is attributed to the molecular conformations of the $\beta$-sheet. Detail data is shown in Table 3. With a decrease in the dissolution time, the content of $\alpha$-helix decreases, which indicates that the dissolution of wool using more effective ionic liquids results in a much stronger cleavage of the hydrogen bonds and disulfide linkages. The data are also well consistent with the corresponding X-ray diffraction patterns.

Quantitative changes in the disulfide bonds. Disulfide bonds, which could serve as crosslinking sites to form the water-stable fibers, are mainly responsible for the high stability and hardness of the fibers. The quantitative changes in the disulfide bonds in the keratins regenerated from different ILs were determined to further understand the microstructural changes, and these results are shown in Fig. 6. With the decreasing dissolution time, which the ILs require for the complete dissolution of goat wool, the content of the disulfide bonds significantly decreased from $113 \mathrm{nmol} \mathrm{mg}^{-1}$ to $2 \mathrm{nmol}$ $\mathrm{mg}^{-1}$, which indicates that the disulfide bonds were seriously destroyed in the dissolution process, which is in accordance with the trend of crystallinity.

Thermal stability analysis. The thermal stability of the raw wool and regenerated keratins was investigated via TGA. From Fig. 7, it can be seen that two stages of decomposition are observed in all cases. There is a small weight loss at about $373 \mathrm{~K}$ due to the evaporation of the incorporated water. The second decomposition between $513 \mathrm{~K}$ and $723 \mathrm{~K}$ could be attributed to the denaturation and degradation of the keratin molecules. ${ }^{2,10,25}$ According to a previous report, ${ }^{45}$ the disulfide bonds are cleaved between $503 \mathrm{~K}$ and $523 \mathrm{~K}$.

The decomposition temperature $\left(T_{\mathrm{d}}\right)$ is defined as the start temperature at which the sample has a weight loss of $5 \%$, and

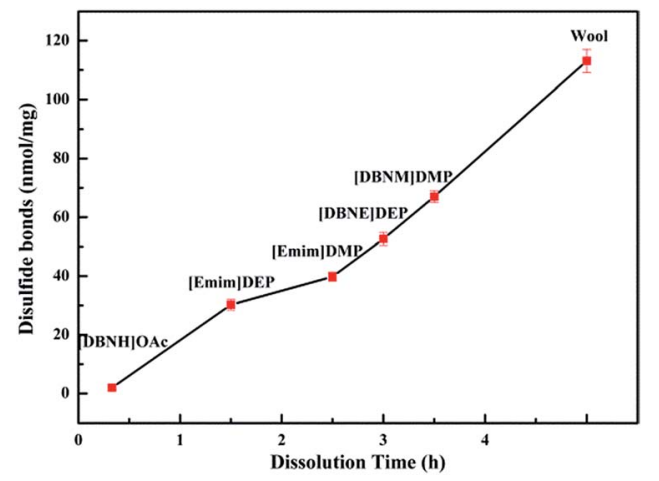

Fig. 6 Changes in the disulfide bonds of goat wool in different ionic liquids.

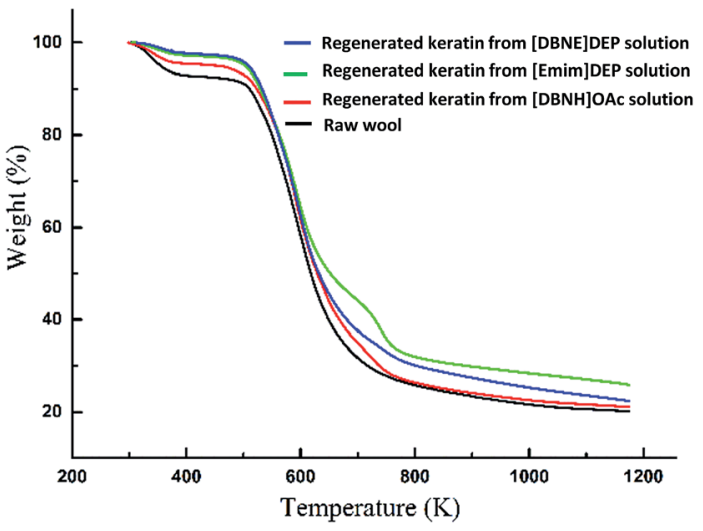

Fig. 7 TGA curves of the raw material and regenerated keratins.

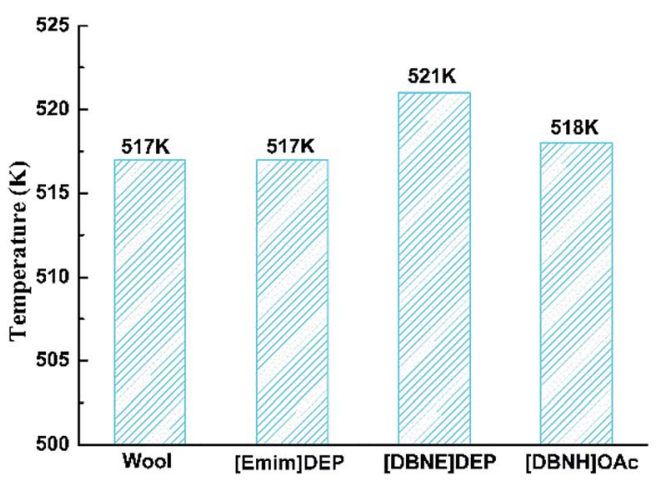

Fig. 8 Decomposition temperatures of the regenerated keratins and raw wool.

the results are shown in Fig. 8. It can been found that the $T_{\mathrm{d}}$ of raw wool and regenerated keratins is between $517 \mathrm{~K}$ and $521 \mathrm{~K}$, with the thermal stability of the regenerated keratins being slightly higher than that of the goat wool, which is in accordance with the previous reports. ${ }^{8}$ The thermal stability of the keratin regenerated from [DBNE]DEP is higher than that of the keratin regenerated from [Emim]DEP and [DBNH]OAc, which is also consistent with the trend of crystallinity.

\subsection{Dissolution capability}

ILs, which have high dissolution capabilities, must meet the requirements of short dissolution time and high mechanical performance for the regenerated keratin, which possesses high crystallinity, a large $\alpha$-helix content, strong thermal stability, and low disulfide bond break ratio. The dissolution capabilities of the various ILs were compared, and Fig. 9 illustrates the relationship between the break ratio of the disulfide bonds, content of $\alpha$-helix in the regenerated keratins, and dissolution time. With a decrease in the dissolution time from $3.5 \mathrm{~h}$ to $0.33 \mathrm{~h}$, the break ratio of the disulfide bonds significantly increased from $40.64 \%$ to $98.26 \%$ and the $\alpha$-helix content was reduced from $57.88 \%$ to $4.53 \%$. In particular, the dissolution time of [DBNE]DEP was $3 \mathrm{~h}$, and its disulfide bonds break ratio and $\alpha$-helix contents were $53.46 \%, 57.88 \%$, respectively, which 


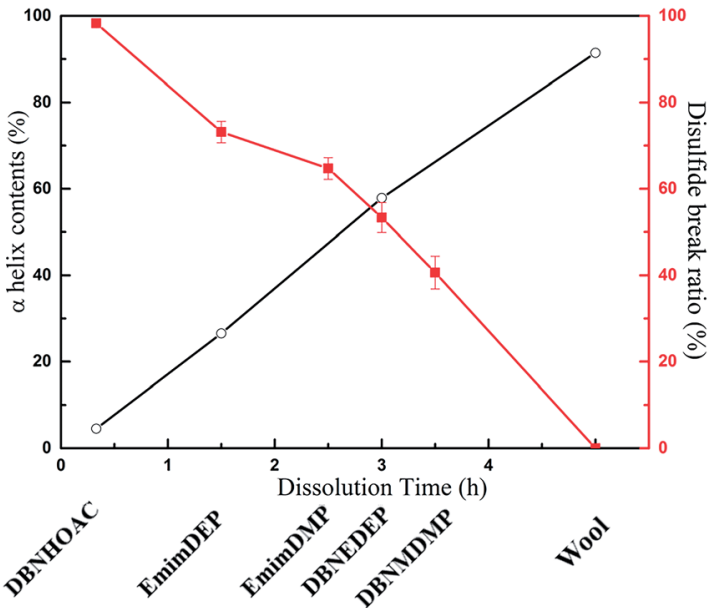

Fig. 9 Relationship between the dissolution time, content of $\alpha$-helix, and disulfide break ratio.

means that [DBNE]DEP is the best IL to dissolve the wool keratin with the highest dissolution capability.

\subsection{Rheological property}

The rheological property of a keratin solution is a significant parameter in the spinning of keratin filaments, which are broadly used in many fields. The rheological property of the IL/keratin solutions using the DEP based ILs were studied. Fig. 10 shows that with an increase in the shear rate $(\gamma)$, the viscosity $(\eta)$ decreases and the logarithmic curve of the shear stress $(\sigma)$ and
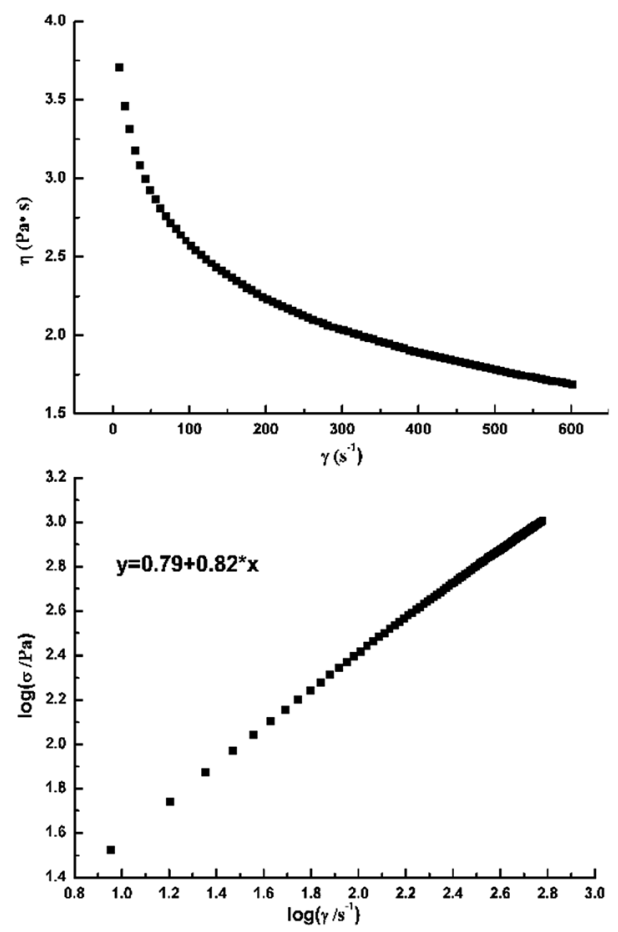

Fig. 10 Dependence of the apparent viscosity on the shear rate and the logarithmic plots of shear stress vs. shear rate of a [DBNE]DEP solution at a mass ratio of $8 \mathrm{wt} \%$ and temperature of $333 \mathrm{~K}$.
Table 4 Non-newtonian index, $n$, with a solution mass ratio of $8 w t \%$

$\begin{array}{lllllllll}\text { Temperature (K) } & 313 & 323 & 333 & 343 & 353 & 363 & 373 & 383\end{array}$

$\begin{array}{lllllllll}\text { [DBNE]DEP } & 0.81 & 0.82 & 0.82 & 0.81 & 0.81 & 0.81 & 0.81 & 0.81\end{array}$

$\begin{array}{lllllllll}\text { [EMIM]DEP } & 0.77 & 0.78 & 0.79 & 0.79 & 0.81 & 0.80 & 0.80 & 0.77\end{array}$

shear rate $(\gamma)$ shows a good linear relationship. According to a previous report, ${ }^{8}$ the higher the value of the non-newtonian index $(n)$, the better the spinnability of a solution. The nonnewtonian index, $n$, of the DEP IL/keratin solutions at different temperatures are shown in Table 4 . The values of $n$, which first increase, and then slightly decrease, are all about 0.8 , which indicates an excellent potential for spinning. Moreover, the best spinning temperature range for the [Emim]DEP IL/keratin solution at $8 \mathrm{wt} \%$ is $343-353 \mathrm{~K}$, whereas that for the [DBNE]DEP IL/ keratin solution at $8 \mathrm{wt} \%$ is $323-333 \mathrm{~K}$, which indicates less energy consumption. Therefore, the solvent and spinning temperature must be carefully chosen to improve the quality of the spinning.

\subsection{Recycling of the ionic liquids}

From the perspective of economic and environmental protection, the reusability of the [DBNE]DEP IL was investigated. After the regeneration of keratin from the IL solution, the liquid phase was condensed by rotary evaporation to recycle the IL. Successive dissolutions were performed five times with the recycled IL at $393 \mathrm{~K}$. The results suggest that the wool keratin can completely dissolve in the recycled IL, and the FT-IR results indicate that compared with the pure IL [DBNE]DEP, the spectra of the recycled IL after 5 runs remain unchanged (Fig. $\mathrm{S} 2 \dagger$ ). Electrospray mass spectrometry results suggest that the molecular weight of the cation and anion of the recycled IL after 5 runs are similar to that of the pure IL [DBNE]DEP (Fig. S3 $\dagger$ ). All these results indicate that the structure of the recycled $\mathrm{IL}$ remains unchanged, which is consistent with the ${ }^{1} \mathrm{H}$ NMR result. The thermal stability of the keratin regenerated from the 5 th recycled IL solution is same as that for the keratin regenerated from the first run (Fig. $\mathrm{S} 4 \dagger$ ). These results also indicate that $[\mathrm{DBNE}] \mathrm{DEP}$ has a good reuse property.

\section{Conclusions}

In summary, the structures of ILs have an important effect on their dissolution capability for wool keratin because they influence the polarity and hydrogen bond basicity of the ILs, which results in different dissolution times and properties of the regenerated keratin. Several ILs exhibit excellent dissolution capabilities. In particular, the dissolution time for [DBNE]DEP to dissolve $8 \mathrm{wt} \%$ wool keratin is $3 \mathrm{~h}$ at $393 \mathrm{~K}$. The crystallinity of the keratin regenerated from [DBNE]DEP is higher than that of the keratin regenerated from [DBNH]OAc and [Emim]DEP, which exhibit slightly shorter dissolution times than that of [DBNE]DEP. Moreover, the keratin regenerated from [DBNE] DEP also exhibits high thermal stability and the content of $\alpha$ helix and disulfide bond break ratio are 57.88\% and $53.46 \%$, respectively. In addition, the [DBNE]DEP IL shows excellent 
performance for recycling and fiber spinning. In light of economics and the environment, [DBNE]DEP is the best IL and it shows a good potential for industry application and studies on the relationship between the structure of the IL and dissolution capability will provide a direction for future research.

\section{Acknowledgements}

This work was financially supported by the 973 Program (2015CB251403), the National Natural Science Foundation of China (21576262), the National Natural Science Fund for Distinguished Young Scholars (21425625), "Recruitment of Outstanding Technologist" of Chinese Academy of Sciences, and Key Program of the National Natural Science Foundation of China (91434203).

\section{Notes and references}

1 A. J. Poole, J. S. Church and M. G. Huson, Biomacromolecules, 2008, 10, 1-8.

2 A. Idris, R. Vijayaraghavan, U. A. Rana, A. F. Patti and D. R. MacFarlane, Green Chem., 2014, 16, 2857-2864.

3 N. Eslahi, F. Dadashian and N. H. Nejad, Prep. Biochem. Biotechnol., 2013, 43, 624-648.

4 R. Fraser, T. MacRae and G. E. Rogers, Keratins: their composition, structure, and biosynthesis, Charles C. Thomas, 1972.

5 K. M. Arai, R. Takahashi, Y. Yokote and K. Akahane, Eur. J. Biochem., 1983, 132, 501-507.

6 J. R. Barone, W. F. Schmidt and C. F. Liebner, J. Appl. Polym. Sci., 2005, 97, 1644-1651.

7 H. B. Xie, S. H. Li and S. B. Zhang, Green Chem., 2005, 7, 606608.

8 S. Zheng, Y. Nie, S. Zhang, X. Zhang and L. Wang, ACS Sustainable Chem. Eng., 2015, 3, 2925-2932.

9 R. J. Block, Ann. N. Y. Acad. Sci., 1951, 53, 608-612.

10 A. Idris, R. Vijayaraghavan, U. A. Rana, D. Fredericks, A. F. Patti and D. R. MacFarlane, Green Chem., 2013, 15, 525.

11 K. Yamauchi, A. Yamauchi, T. Kusunoki, A. Kohda and Y. Konishi, J. Biomed. Mater. Res., 1996, 31, 439-444.

12 E. K. Bang, M. Lista, G. Sforazzini, N. Sakai and S. Matile, Chem. Sci., 2012, 3, 1752-1763.

13 H. Rhodes, B. Potter and A. Widra, Mycopathologia, 1967, 33, 345-348.

14 R. Cecil and J. McPhee, Adv. Protein Chem., 1959, 14, 255389.

15 R. Asquith and N. Leon, Chemistry of Natural Protein Fibers, Springer, 1977, pp. 193-265.

16 A. Vasconcelos, G. Freddi and A. Cavaco-Paulo, Biomacromolecules, 2008, 9, 1299-1305.

17 M. Smiglak, J. M. Pringle, X. Lu, L. Han, S. Zhang, H. Gao, D. R. MacFarlane and R. D. Rogers, Chem. Commun., 2014, 50, 9228-9250.
18 Y. Ji, J. Chen, J. Lv, Z. Li, L. Xing and S. Ding, Sep. Purif. Technol., 2014, 132, 577-583.

19 A. Idris, R. Vijayaraghavan, A. Patti and D. MacFarlane, ACS Sustainable Chem. Eng., 2014, 2, 1888-1894.

20 Y. L. Zhao, X. M. Liu, J. J. Wang and S. J. Zhang, J. Phys. Chem. $B, 2013$, 117, 9042-9049.

21 Z. Liu, H. Wang, Z. X. Li, X. M. Lu, X. P. Zhang, S. J. Zhang and K. B. Zhou, Mater. Chem. Phys., 2011, 128, 220-227.

22 Y. Li, X. M. Liu, S. J. Zhang, Y. Y. Yao, X. Q. Yao, J. L. Xu and X. M. Lu, PCCP, 2015, 17, 17894-17905.

23 Y. L. Zhao, X. M. Liu, J. J. Wang and S. J. Zhang, ChemPhysChem, 2012, 13, 3126-3133.

24 J. E. Plowman, S. Clerens, E. Lee, D. P. Harland, J. M. Dyer and S. Deb-Choudhury, Anal. Methods, 2014, 6, 7305-7311.

25 R. Li and D. Wang, J. Appl. Polym. Sci., 2013, 127, 2648-2653. 26 Q. T. Chen, A. R. Xu, Z. Y. Li, J. J. Wang and S. J. Zhang, Green Chem., 2011, 13, 3446-3452.

27 M. Shimo, M. Abe and H. Ohno, ACS Sustainable Chem. Eng., 2016, 4, 3722-3727.

28 J. X. Long, X. H. Li, L. F. Wang and N. Zhang, Sci. China: Chem., 2012, 55, 1500-1508.

29 D. M. Phillips, L. F. Drummy, R. R. Naik, C. Hugh, D. M. Fox, P. C. Trulove and R. A. Mantz, J. Mater. Chem., 2005, 15, 4206-4208.

30 Q. Wang, Y. Yang, X. Chen and Z. Shao, Biomacromolecules, 2012, 13, 1875-1881.

31 A. M. Stepan, A. W. T. King, T. Kakko, G. Toriz, I. Kilpeläinen and P. Gatenholm, Cellulose, 2013, 20, 2813-2824.

32 Y. Nie, C. Li, A. Sun, H. Meng and Z. Wang, Energy Fuels, 2006, 20, 2083-2087.

33 X. Jiang, Y. Nie, C. Li and Z. Wang, Fuel, 2008, 87, 79-84.

34 Y. Fukaya, K. Hayashi, M. Wada and H. Ohno, Green Chem., 2008, 10, 44-46.

35 J. L. Kaar, A. M. Jesionowski, J. A. Berberich, R. Moulton and A. J. Russell, J. Am. Chem. Soc., 2003, 125, 4125-4131.

36 T. W. Thannhauser, Y. Konishi and H. A. Scheraga, Methods Enzymol., 1987, 143, 115-119.

37 K. Y. Chan and B. P. Wasserman, Cereal Chem., 1993, 70, 22.

38 W. Zhao, R. Yang, Y. Zhang and L. Wu, Green Chem., 2012, 14, 3352.

39 H. Xu and Y. Yang, ACS Sustainable Chem. Eng., 2014, 2, 1404-1410.

40 H. Xu, Z. Ma and Y. Yang, J. Mater. Sci., 2014, 49, 7513-7521. 41 J. R. A. Pearson and P. M. J. Tardy, J. Non-Newtonian Fluid Mech., 2002, 102, 447-473.

42 Y. Zhang, X. Tu, D. Li and H. Wang, Polym.-Plast. Technol. Eng., 2010, 47, 688-691.

43 S. Zhang and F. Huo, GEE., 2016, 1, 75-78.

44 E. Wojciechowska, A. Włochowicz and A. WesełuchaBirczyńska, J. Mol. Struct., 1999, 511, 307-318.

45 P. J. Davies, A. R. Horrocks and M. Miraftab, Polym. Int., 2000, 49, 1125-1132. 